\title{
La crítica literaria en los orígenes del periodismo
}

Recibido: 04/07/2010

\author{
Luis Alejandro NitRIHUAL VALDEBENITO \\ Universidad de La Frontera (Chile) \\ uisnitrihual@gmail.com \\ Alberto Javier MAYORGA RoJEL \\ Universidad de La Frontera (Chile) \\ amyorga@ufro.cl
}

Aceptado: 11/01/2011

\begin{abstract}
Resumen
El presente trabajo expone las articulaciones teóricas que sustentan un estudio acerca de de la crítica literaria desarrollada en medios de prensa. Se plantea una discusión teórica a partir de autores como Terry EAGLETON, Jürgen HABERMAS, Albert CHILLÓN y otros que han elaborado un planteamiento sobre el tema. Asimismo, se busca situar la discusión en el contexto americano, específicamente chileno

Palabras clave: Crítica Literaria, Ilustración, Prensa.
\end{abstract}

\section{Literary criticism in the origins of journalism}

\begin{abstract}
This paper exposes the theoretical framework that underpin a study on literary criticism in press. There is a theoretical discussion of authors such as Terry EAGLETON, Jürgen HABERMAS, Albert CHILLÓN and others that have developed an approach on the subject. It also seeks to situate discussion in the context, specifically Chilean.
\end{abstract}

Key words: Literary Criticism, Illustration, Press.

\section{Referencia normalizada}

NITRIHUAL VALDEBENITO, Luis A. y MAYORGA ROJEL, Alberto J. (2011): "La crítica literaria en los orígenes del periodismo". Estudios sobre el mensaje periodístico. Vol. 17, núm. 1, págs.: 183194. Madrid, Servicio de Publicaciones de la Universidad Complutense.

Sumario: 1. Objetivos, propósito y proyecciones de la investigación. 2. Liminares y definiciones. 3. Crítica Literaria. Rasgos de un fenómeno ilustrado en decadencia. 4. La Crítica Literaria como género periodístico (CLP). 5. Conclusiones. 6. Referencias Bibliograficas

\section{Objetivos, propósito y proyecciones de la investigación}

El propósito de este trabajo es comprender el valor de la crítica como parte del circuito de consumo literario, su función como constructora del canon literario y su importancia en la concreción de una opinión y esfera pública burguesa.

En una primera aproximación al objeto de estudio, llama la atención que en la agenda de investigación en comunicación en Chile -demostrada de manera fundamental en investigaciones financiadas por Fondo de Desarrollo Científico y tecnológico (FONDECYT)- aparece un rasgo sugerente y relevante para nuestra investigación: no hay presencia de investigaciones que se aboquen a trabajar el discurso de la crítica literaria ejercida en los medios de prensa.

\footnotetext{
${ }^{1}$ Trabajo financiado por el Consejo Nacional de la Cultura y las Artes, Fondo Nacional de Fomento del Libro y La Lectura (Chile), Primer Semestre 2010. Proyecto ${ }^{\circ} 8892-7$
} 
Este dato inicial nos obliga a reflexionar sobre las razones de dicha ausencia, probablemente vinculada al monopolio de ciertos temas y problemas que DEL VALLE (2004) ha descrito en su libro Metainvestigación de la Comunicación en Chile². Pero por otro lado, lo que resulta aún más interesante, es que el tema de la literatura y el periodismo, como dos disciplinas convergentes, no ha sido tratado en profundidad en Chile.

Esto último es llamativo pues como proponen HABERMAS (2006), EAGLETON (1999), Gomis (1989), SANTAMARÍa SuAREZ y CASALS CARro (2000) y tantos otros, el discurso que desde ahora llamaremos CLP (Crítica Literaria Periodística) ha estado presente largamente desde el siglo XVIII en adelante tanto en Europa como en América, siendo parte de una tradición ilustrada que sigue hasta nuestros días: con mayor o menor presencia, con mayores o menores problemas, dependiendo del sistema mediático. Como señalan Santamaría Suarez y Casals Carro (2000: 314): "La crítica es el género periodistico más antiguo puesto que como actividad intelectual ya estaba codificada antes de que naciera el periódico de masas”.

\section{Liminares y definiciones}

En principio comprender es definir, es intentar una aproximación más o menos precisa de conceptos que tienen una larga matriz de significados que lo arraigan a la cultura. En este sentido, Raymond Williams (2008) revisando etimológicamente el origen de la palabra crítica señala que ésta se ha tornado compleja pues en su sentido general hace referencia al hecho de descubrir errores, pero de manera específica, y desde el siglo XVII, al acto de juzgar la literatura y obras artísticas. Como señalaba DEKKER en 1607 "pararse en el blanco de la crítica [...] para ser acribillado” (citado en Williams, 2008: 85). Por tanto, la palabra crítica evolucionó desde el siglo XVII hacia Censura y en un sentido especializado hacia gusto, cultivo y más tarde, cultura y discriminación.

Precisamente en este sentido, cuando se recurre a una definición de diccionario, la palabra crítica correponde a la actividad que examina y juzga una obra artística. Una definición de crítica como prolongación del arte coloca en evidencia que nos encontramos ante un texto generado como reacción a un primigenio texto, que es el literario. La mediación es evidente: de un lado se encuentran los textos generados por autores, del otro lado están los lectores y en medio se encuentra esta actividad devenida institucionalizada que realiza una lectura que ya no es el primer texto sino un nuevo texto; tan complejo como el primero.

Como la crítica es una actividad intitucionalizada se han generado espacios para su divulgación. Las teorías pragmáticas de la comunicación señalan que finalmente el texto es completado por el lector, que debe entenderse en el caso de la crítica ya no sólo con el texto literario, también debe hacerlo con un texto que habla sobre él. En un doble momento el lector debe confrontar sus lecturas. Esto genera una tensión

${ }^{2}$ Del Valle ha señalado cinco puntos en los que se ha concentrado la agenda: a) La televisión; b) Nuevas tecnologías de la información y comunicación; c) Lógicas de consumo; d) Comunicación y política; e) Construcción de noticias deportivas. 
y un movimiento dialéctico en las interpretaciones entre el texto literario y un texto parasitario (CARRASCO, 1995), como es la crítica literaria. Pero dejemos este carácter polémico del discurso crítico para más tarde y veamos una definición de lo que es la crítica literaria:

"En un sentido amplio, el término de Crítica Literaria llega a significar en general pensamiento y reflexión sobre la literatura; con lo que engloba no sólo el campo propio de la Teoría literaria, sino, como decíamos antes, que se llega a igualar en la práctica con el total de la Ciencia Literaria” (García-Berrio, A. y Hernández Fernández, T., 2004:24).

Por otro lado, como uno de los canales por los que ha transitado la crítica durante siglos son los medios de prensa, este discurso ha sido considerado dentro de lo que se conoce como "periodismo cultural" (RIVERA, 1995). Justamente en este sentido, y llamando la atención sobre la importancia de la crítica en los medios de prensa, Llorenç Gomis (1989) en su libro Teoría dels generes periodístics ha señalado lo siguiente:

"La crítica de llibres ha comencat per ser informació pura i simple [...] La crisi de la crítica després del 1830 - escriu Roger Fayolle - s`explica per un esdenveniment capital en la història de la literatura: el desemvolupament de la premsa trastorna les condicions de la producciò literària” (GomIs, 1989:154).

De modo que las definiciones del comienzo, y el lúcido acercamiento de Gomis, no hacen otra cosa que reproducir una visión de muy larga data y que inscriben a la crítica al interior de la tradición ilustrada.

La crítica, al ser incorporada tempranamente en la prensa periódica, fue incluida en el denominado "periodismo cultural". Evidentemente se trata de un planteamiento que dintingue (o intenta distinguir) el estilo periodístico del estilo literario. No obstante esto, la dificultad es mayúscula si se considera la mezcla de géneros presentes en los primeros periódicos.

Como bien señala EAGLETon (1999), hay que considerar que los periódicos donde germinó la crítica literaria eran promiscuos en sus relaciones genéricas, por lo cual establecer una separación entre comentario e información, por ejemplo, era imposible en el siglo XVIII, XIX e incluso hoy. Desde este supuesto ha trabajado Albert CHILLÓn (1999) en su libro Periodismo y Literatura. Una tradición de relaciones promiscuas; el autor describe la debilidad de fronteras entre periodismo y literatura y cómo más bien estas se complementan y enriquecen.

Jürgen HABERMAS (2006: 80) señala, por su parte, que los semanarios y periódicos de crítica literaria y artística son propios del siglo XVIII cuando el fin ilustrado los convertía en esenciales para una vida civilizada. En esta medida, la función del crítico en periódicos ingleses del siglo XVIII como Tattler o Spectator es definida por ADIsson como la de un Censor of Manners or Morals. La fluidez de géneros y la policronía temática le permite a este tipo textual tener valor como estamento de discusión de la burguesía. Se consolida de este modo un espacio de la opinión pública formal: la que se da en los periódicos.

Por otro lado, el papel de antesala y de mediación convierte a la crítica literaria en un punto importante del circuito de interpretación de las obras literarias y de la 
realidad social que las envuelve. Cabe reflexionar en el punto polémico de si la mediación de la crítica es fundamental en el circuito literario: ¿qué valida a este lector (el crítico) para que sus inferencias sean válidas para dicho texto?.

Se trataría, a juicio de Gomis (1989:156), de un lector especialmente calificado para ayudar a los lectores a entender una obra. También de un lector avisado que es capaz de apreciar la relación entre el propósito, las ambiciones del autor y los resultados obtenidos. Señalan GARCíA-BERRIO y HERNÁNDEZ FERNÁNDEZ:

“Conviene insistir especialmente en el aspecto del análisis y la valoración mediadora de la crítica literaria” (GArcía-Berrio, A. y Hernández Fernández, T. 2004: 25).

"La crítica literaria es por tanto una disciplina activa y análitica, que tiene que contar con criterios de base en los que fundar sus diagnósticos como fundamento de sus valoraciones” (Ibid., 2004: 24).

Ahora bien, este carácter mediador ha producido que "por su carácter secundario, por la desgracia temporal de haber aparecido después de los textos y los acontecimientos que supuestamente trata” (SAID, 2008: 74) la crítica no sea tomada en toda su complejidad. No obstante, la crítica corresponde a un discurso que si bien remite a otros, posee características particulares, pues al igual que los textos literarios contiene una estrategia textual narrativa compleja pues es: ética, estética y parasitaria (JOFRÉ, 1997).

Por ser un discurso que remite a otros, tiene un fuerte apego al poder, dada la posibilidad de cuestionar a otros discursos, lo que siempre causa conflictos con los escritores. Estos -en una suerte de amor y odio- buscan se criticados y odian a la crítica cuando no los favorece. No es raro, por tanto, escuchar iracundas flechas lanzadas por los escritores, en donde llaman a los críticos "escritores fracasados" (Alone, 1997).

Como señala JOFRÉ (1997), la crítica además de una estrategia estética tiene también una estrategia ética. Esto alude a la posibilidad que tiene de producir interpretaciones que refuerzan la presencia de determinadas obras en el canon de textos que "debe leerse" para ser considerado un hombre "culto". Este fenómeno es especialmente importante en la crítica literaria periodística pues la mediación que produce es muchas veces discriminante a la hora de que el lector adquiera una obra.

En particular, si se atiende a la función que entregan los teóricos a la crítica producida en medios masivos: "El crític té la funció d`escollir i explicar després per què una obra li ha semblat interessant” (Gomis, 1989: 156). En un sentido general, se trata de juzgar una obra literaria volviéndola interesante para un público masivo que reclama el acceso a la cultura (como bellas artes).

Hay que consignar eso sí, que esta masividad de la crítica literaria ha producido su propia transformación junto con la estructura general de la información. Fénomenos comerciales como la masificación de la publicidad al interior de los medios han comprimido las expresiones de crítica hasta su eliminación en algunos medios de prensa o su reducción a una faceta informativa, tipo reseña. Esto rompe, como es lógico, la vieja relación entre literatura y cultura como espacios de diálogo. 
La función del crítico como Censor of Manners and Morals debería revisarse. No creemos que haya desaparecido, tampoco creemos que la crítica se haya objetivizado y desidiologizado, más bien por el contrario es muy posible que la crítica hoy se incline hacia una función tecnocrática mercantil, donde su valor principal es el de validar y consolidar la expansión del mercado editorial.

\section{Crítica literaria. Rasgos de un fenómeno ilustrado en decadencia}

La crítica literaria pareciera desde un planteamiento inicial y superficial, un tipo de texto periodístico relacionado de manera evidente con la literatura y que por tanto, debiera ser abordado por especialistas en literatura o, en su defecto, periodistas con mayor o menor especialización en literatura. Por tanto, no ingresa en los estudios clásicos en comunicación periodística, como sí lo hacen naturalmente las noticias, editoriales y reportajes.

Si es necesario defenderse de tal planteamiento habría que hacerlo doblemente: a) primero, pues la crítica de arte y literaria se encuentran vinculadas desde sus inicios con la formación y consolidación de una opinión pública, primero pre burguesa y luego propiamente burguesa en el siglo XVIII; b) y segundo, pues la evolución de la crítica literaria a lo largo de la historia mediática se encuentra vinculada, por tanto, con la evolución cultural (social, económica y política) y de expansión del capital en sus distintas transformaciones.

La crítica literaria, particularmente la que comienza a aparecer en los medios de prensa y revistas en Inglaterra y Francia a fines del siglo XVII y luego a lo largo de todo el siglo XVIII, no será por cierto el texto especializado en literatura que se conoce en la actualidad. Se trata más bien de un texto que busca ilustrar, dialogar en cuestiones de gusto, moral y política. Como señala el crítico literario Omer EMETH (Emilio Vaïsse): "La belleza literaria es sencillamente el resplandecimiento de la verdad" (en Dyson, 1965: 30).

Se trata del diálogo racional, del acuerdo tácito en que los hombres, mediante la circulación libre de las ideas, son capaces, sin presión no racional, de discutir y aprehender sobre las artes, las ciencias y la moral para lograr la mayoría de edad que tan agudamente señaló y soñó Kant (SLOTERDIJK, 2007).

Por tanto, como acertadamente ha señalado EAGLETon (1999) la crítica en sus inicios es más bien cultural que literaria. La reflexión específica sobre tal o cuál libro es un momento marginal de un diálogo mayor sobre las normas de cortesía, la libertad de los hombres, las leyes, la sensibilidad estética, las relaciones conyugales, jurídicas, etc. En esta medida, emprender un análisis de la evolución de la crítica literaria periodística en Chile (o cualquier país latinoamericano desde fines del siglo XVIII hasta la actualidad) es un trabajo aún por hacer, y que da cuenta de la gestación de la esfera y opinión pública moderna.

En este último punto hay que considerar una situación histórica necesaria de tener en cuenta en un análisis de la crítica literaria de los países americanos. Se trata de la evolución y formación del Estado y de la burguesía. Esta no ha tenido el mismo trayecto que en Europa pues como señala Jorge LARRAín, citando a Claudio VéLIZ: 
"En América Latina se dan cuatro ausencias históricas claves que condicionan los orígenes de la modernidad y que marcan diferencias sustanciales con la modernidad europea: la ausencia de feudalismo, la ausencia de disidencia religiosa, la ausencia de algo parecido a la Revolución Francesa” (LARRAín, J., 2005: 34).

Del pensamiento de Jorge LARRAín resulta interesante que las claves del desarrollo identitario latinoamericano tiene como norte a la ilustración; que guió a los “padres de la patria” en la formación de la nación. Ahora bien, por otro lado, cuestión no tomada suficientemente en cuenta por los analistas de medios de comunicación en Chile, la evolución histórica de conformación de las distintas capas sociales muestra que la tendencia, desde el proceso de independencia y durante las coyunturas históricas militaristas y golpistas de 1823, 1921 y 1980, ha sido el intento de restaurar, al precio que sea, el ejercicio del poder dominante de un grupo específico de la burguesía mercantil chilena.

No puede extrañar que los medios de comunicación correspondan a la ideología de una elite política que ha sobrevivido a las distintas coyunturas políticas: democracia socialista, dictadura política, democracia pactada. Por otro lado, no es menos relevante considerar que dentro de este panorama, muy probablemente (pues habría que desarrollarlo con mayor profundidad y diacronía de un análisis de la crítica literaria chilena) las figuras de mayor realce como Omerth EMETH, Ignacio VALENTE y ALONE sean conservadores, con matices ${ }^{3}$ y voces muy fuertes que buscan restaurar constantemente una matriz de literatura universal decimonónica.

La crítica literaria por otro lado, desde sus inicios, ha sido más que literaria (o fundamentalmente literaria) cultural en el sentido de normalizadora de determinados valores que un segmento de la sociedad quiere preservar para mantener su posición hegemónica. EAGLETON (1999) ha destacado cómo en la Inglaterra de fines del siglo XVIII la crítica literaria constituyó un espacio de asentamiento de los valores de la burguesía, un espacio de consenso y de libre tránsito de las opiniones.

En este sentido, el mismo Alone llamaba crónica a su espacio semanal en el diario chileno El Mercurio. En su crónica el crítico se extendía sobre temas de contingencia, orientaciones religiosas, filiaciones intelectuales y evidentemente de literatura.

El crítico literario, por tanto, es tradicionalmente (es decir desde su difusión en el siglo XVIII) un actor clave al ser portavoz de la opinión pública. Señala EAGLETON (1999) que el trabajo de la crítica es justamente disentir y desestabilizar la esfera pública. En este sentido, aunque románticamente críticos como ALONE, destacan la poca importancia que debe tener el ejercicio de la crítica para los autores y la sociedad, no cabe duda que su impacto, al menos durante el siglo XVIII y XIX, es relevante para la concreción de una esfera pública informada y que se pretende ilustrada.

${ }^{3}$ En un trabajo anterior (Nitrihual, 2006) hemos mostrado cómo AlONE, desde su tribuna en el diario chileno El Mercurio, sacó a la luz a escritoras de renombre como Gabriela Mistral, Marta Brunet y otras. En este sentido, este crítico pareciera responder en algunos aspectos a un crítico que se deja llevar por su sensibilidad estética. 
La circulación de discursos públicos, por intermedio de una prensa crecientemente masiva, obedece a una expansión de la esfera pública de las sociedades burguesas, a la generación de una matriz de discursos que sustentaron el nuevo orden de intercambio racional de ideas y de "libre" circulación de información.

Dentro de esto, la circulación de un género como la crítica literaria, consolida una matriz discursiva ilustrada dentro de las sociedades capitalistas que hacen de la circulación de información un bien necesario. Ahora bien, paradójicamente, esta masividad que cobra el diálogo que antes se mantenía en los salones del siglo XVII es su propia deformación, posterior replegamiento hacia segmentos específicos de intelectuales y su desaparición o transformación en los medios masivos.

La crítica literaria que aparece en el siglo XVIII en Inglaterra reemplaza el aristocrático diálogo de los salones y posteriores cafés por una opinión que comienza a ser divulgada por los periódicos y gacetas; como brillantemente señala Terry EAgLETON:

“A comienzos del siglo XVIII, pues el principio burgués de la comunicación abstracta libre e igualitaria es elevado desde la plaza del mercado a la esfera del discurso para mistificar e idealizar relaciones sociales burguesas auténticas” (EAGLETON, T., 1999: 30).

El intercambio de un bien como la "opinión pública” se inserta dentro de un intercambio económico y político que resiste al cambio y que contribuye a sustentar a la clase política dominante.

¿Pero en qué ha mutado la crítica literaria? ¿cuál es su transformación? No es una pregunta fácil dado que hablamos de un género muy variado y presente de manera transversal en los periódicos. La respuesta, no obstante, puede ser una aventura hipotética sustentada en la evolución tanto de los medios como de la industria literaria.

Ya en el siglo XVI comienza una decadencia del mecenazgo literario y una constante y poderosa formación de libreros. Esto va de la mano del desarrollo tecnológico de la imprenta y edición, los avances educativos y la expansión de una masa lectora ávida de consumir literatura. Tres fenómenos propios de la sociedad moderna entran en juego en la producción de crítica literaria en los medios de prensa:

A) En el plano estrictamente literario, la formación de un crítico especialista o profesional produce de manera creciente una búsqueda de personalidad y estilo en los críticos. Este culto al estilo es una búsqueda individualista al reconocimiento de un crítico que se transforma en un conocedor obsesivo de la creciente cantidad de libros que se producen. Como ha destacado, entre otros, SLOTERDIJK (2002: 32), en una sociedad donde la lucha por el reconocimiento es una acción primordial, el desprecio alcanza cotas endémicas. De modo que no extrañará que muchos críticos se enfrenten entre ellos por el reconocimiento de su labor.

Vinculado a lo anterior, los factores políticos y económicos salen a relucir en la producción de crítica. Políticamente, dado que en una formación social (como ha destacado Michel FouCAULT) existe una lucha por asirse del control del discurso, la 
crítica literaria transitará hacia una fuerte politización y dogmatismo. En este sentido, las publicaciones de crítica literaria en el siglo XIX se caracterizan por tener un tono jurídico, ya no son un ámbito de consenso sino el lugar de enfrentamiento de la lucha de clases. Bajo estas presiones, la esfera pública se deforma.

B) Desde el punto de vista económico, la esfera pública es invadida por la agresividad del mercado. El paso que ha señalado Terry EAGLETON (1999) del mecenazgo a los libreros y luego a las editoriales hacen que en la creación de una obra el público masivo emerja como una fuerza violenta en la que el crítico hace las veces de receptor mediador y se constituya en el "banquero simbólico" de la industria editorial.

Señalando estas mutaciones que inauguran la modernidad, SLOTERDIJK (2007) ha destacado a la globalización como el eje sobre el cual se ha articulado la expansión del capital y su transformación en dinero, texto e imagen.

En el caso de Chile los primeros periódicos tienen un carácter educativo ilustrado. Dado el proceso histórico de instalación de la ilustración en América -no su tránsito desde formas pre burguesas, y burguesas-, cabe preguntarse por el camino que ha seguido la crítica literaria.

En su libro Historia y Crítica de la Opinión Pública, Jürgen Habermas (2006) ha llamado la atención sobre la importancia de la crítica literaria y de arte en la formación de una inicial ilustración:

"Los periódicos de crítica artística y cultural, como instrumentos que son de la crítica artística institucionalizada, son creaciones típicas del siglo XVIII [...] Por un parte, la filosofía es ya sólo posible como filosofía crítica, y la literatura y el arte son sólo posibles en conexión con la crítica literaria y artística [...] Por otro lado, adquirió también el público ilustración sólo por la vía de la apropiación crítica de filosofía, literatura y arte: sólo por esta vía llegó a comprender el proceso vivo de la Ilustración” (HABERMAS, J., 2006: 79).

La crítica literaria europea moderna nace de la lucha contra el Estado absolutista. Como puede leerse en HABERMAS (2006) y EAGLETON (1999) el concepto de crítica literaria va íntimamente ligado, durante el periodo de la Ilustración, a la consolidación de la esfera pública.

Ya en el siglo XX, la crítica literaria responde a nuevos requerimientos, íntimamente relacionada con las vanguardias. Esto se deja sentir con fuerza, por ejemplo en las reflexiones críticas del modernismo español. Por otro lado, a mediados del siglo XX surge un movimiento que busca delimitar la obra a sus aspectos sociales, económicos, políticos e incluso éticos.

En el caso chileno, en el diario La Aurora de Chile (1812-1813) se publicaron reseñas de libros extranjeros que servían de base para la difusión de ideas libertarias relacionadas con las inquietudes independentistas. No obstante, la crítica literaria apareció formalmente con Andrés BELLO.

En 1842, el Movimiento o Generación del '42, constituido por artistas, abogados, educadores, ingenieros y periodistas abrió el país al terreno intelectual. Posteriormente, la aparición de El Semanario de Santiago, órgano de la Sociedad 
Literaria formada por José Victorino LASTARRIA la Revista de Valparaíso y el El Museo de Ambas Américas, se transformaron en parte importante del desarrollo crítico literario chileno.

A comienzos del siglo XX la crítica literaria nacional se había consolidado. Ya desde 1973 se ha discutido mucho acerca de la situación de la literatura, la crítica literaria y la cultura. La disminución significativa de los espacios culturales, junto a una concentración de la propiedad y de las fuerzas productivas ha sido la tónica de lo que GUERRERo (1995) ha denominado “apagón cultural”.

\section{La crítica literaria como género periodístico (CLP)}

Eduardo GUERRERo (1995) señala que la crítica literaria se ejerce en tres grandes áreas: periodismo, universidad e instituciones formales. Para Manuel JofRÉ (1995), la crítica periodística se manifiesta en bibliografías, reseñas, notas, comentarios y reportajes sobre libros. Una de sus particularidades es estar escrita para consumo masivo, lo que implica menores niveles de conocimiento del desarrollo de las teorías literarias (Literatura, Lingüística, Semiótica, etc.) que la académica, que se dirige a público especializado.

Para entender de manera clara las características de la crítica literaria periodística hay que tener presente dos grandes particularidades:

- Lenguaje: se trata de un discurso caracterizado por ser claro y sintético, lo que hace que en muchas ocasiones se le acuse de falta de originalidad.

- Espacio: en relación con esta característica hay consenso en señalar que los espacios destinados a ejercerla se encuentran en franca decaída en los medios locales, y esto coincide con el llamado "apagón cultural” (GUERRERO, 1995: 90). En relación este "apagón cultural” sucedido en Chile desde 1973 a la fecha, cabe recordar el intento llevado a cabo en 1999 por el desaparecido diario El Metropolitano que en sus comienzos publicaba un semanario cultural llamado Diagonal y dedicado exclusivamente a temas literarios y culturales. Dicho suplemento al poco de andar debió cambiar de formato a una revista que sólo trataba de literatura en sus últimas páginas y el resto era farándula. Finalmente desapareció no sólo la revista sino también el diario, lo que evidencia un proceso mucho mayor de concentración mediática y reducción del espectro cultural a unos pocos diarios.

Asistimos a un fenómeno de desplazamiento de lo cultural a espacios íntimos e ínfimos, norma general en los medios de masas. Esto reduce notoriamente las críticas literarias a simples reseñas bibliográficas lo cual empobrece su contenido. Aún así, en los espacios donde puede seguir haciéndose supone "un ejercicio de síntesis interesante y que debe continuar” (GUERRERO, 1995: 91).

La crítica literaria periodística, en palabras de Rodrigo CÁnovas (1995), tiene como función la información y valoración de obras literarias, estableciéndose un contacto directo con el lector masivo de periódicos. Por tanto es un género argumentativo (de opinión) aunque también cumple con una clara misión informativa. Debemos tener presente que el género de opinión está sujeto a reglas de juego limpio que Jofré (1997) ha denominado “estrategia ética” u honestidad intelectual y responsabilidad. 
El problema que presencia CÁNOvAs (1995: 115) en la crítica periodística es la subestimación del lector, al que se le considera "insulso, arratonado, talquino". La subestimación del lector lleva a que los textos sean tan simplones que no vayan más allá de señalar cuál libro comprar y cuál no. Es preciso agregar una contextualización problemática a lo que se ha señalado sobre CLP, para incluirla en un contexto movedizo que permita enfrentar estos discursos en el marco de estudios mediáticos.

Con todo, la crítica literaria periodística es un tipo de discurso de necesaria investigación pues ha contribuido a afianzar la esfera pública cultural, a generar procesos de canonización de determinadas obras, que a su vez, como ha señalado SULLÀ (1998: 11), ha determinado la identidad de las naciones.

\section{Conclusiones}

El trabajo que hemos realizado en esta investigación busca consignar el estatuto de discurso mediático de larga tradición de la Crítica Literaria Periodística. Esta tiene entre sus funciones la conformación de la esfera y opinión pública y la difusión cultural, que ratifica la matriz ilustrada de los primeros periódicos y la importancia de la crítica como mediación entre escritor y lector (EAGLETON, 1999; HABERMAS, 2006).

En este sentido, hemos llamado la atención sobre el carácter polémico de este texto y, asimismo, del crítico. Este tiene que vérselas con tener que juzgar a escritores que se quejan de la parcialidad de este ejercicio cada vez más escaso en los medios de comunicación.

En este último aspecto hay que consignar que la crítica, que durante los siglos XVIII, XIX y XX tuvo una importante presencia en los medios de prensa, ha comenzado a desaparecer o desplazarse hacia públicos segmentados específicos en revistas especializadas. Este fenómeno tiene relación, asimismo, con la desaparición de todo lo que huele a crítica en los medios de comunicación, en el caso chileno, aplastados también por un proceso de concentración de su propiedad y reducción y estandarización de sus contenidos. Esto último es lo que ha dado a llamarse "apagón cultural”.

En este sentido, es interesante constatar que los primeros periódicos chilenos tenían un estrecho vínculo con lo literario, pero sin embargo hoy se conserva no sin problemas el suplemento Revista de Libros del diario El Mercurio, los demás medios han optado por eliminar o disminuir hasta la reseña los espacios dedicados a la difusión y discusión cultural.

Otro aspecto que resulta interesante, es que la crítica literaria ejerce también una mediación entre la industria editorial y los lectores, lo cual nos lleva a plantear la relación problemática entre crítica e industria cultural. Esta relación es doblemente compleja si se establece la naturaleza mediática, y, por tanto, la inserción de la crítica literaria periodística en la industria de los medios de comunicación. 


\section{Referencias bibliográficas}

ALONE (Hernán DÍAZ ARRIETA) (1997): El vicio impune: 50 años de crónica. Santiago de Chile, RIL.

ALONSO, María Nieves; RODRÍGUEZ, Mario; TRIVIÑOS, Gilberto (Eds., 1995): La Crítica Literaria Chilena. Concepción (Chile), Anibal Pinto.

CÁNOVAS. Rodrigo (1995): “¿De qué crítica estamos hablando?” en en ALONSO, María Nieves; RODRÍGUEZ, Mario; TRIVIÑOS, Gilberto (Eds.) (1995): La Crítica Literaria Chilena. Concepción, Anibal Pinto, pp. 113-117.

CARRASCO, Iván (1995): “La crítica literaria en tiempos de crisis”, en ALONSO, María Nieves; RODRÍGUEZ, Mario; TRIVIÑOS, Gilberto (Eds.) (1995): La Crítica Literaria Chilena. Concepción, Anibal Pinto., pp. 113-117.

CHILLÓN, Albert (1999): Literatura y periodismo: Una tradición de relaciones promiscuas. Barcelona, Universitat Autónoma de Barcelona.

DEL VALLE, Carlos (2004): Metainvestigación de la Comunicación en Chile. Tendencias y críticas. Temuco-Chile, Ediciones Universidad de La Frontera.

DYSON, John (1965): La evolución de la crítica literaria chilena. Santiago de Chile, Ed. Universitaria.

EAGLETON, Terry (1999): La función de la crítica. Barcelona, Paidós.

GOMIS, Llorenç (1989): Teoría dels gèneres Periodìstics. Barcelona, Generalitat de Catalunya.

GARCÍA-BERRIO, Antonio y HERNÁNDEZ FERNÁNDEZ, Teresa (2004): Crítica Literaria: iniciación al estudio de la literatura. Madrid, Cátedra.

GUERRERO DEL RÍO, Eduardo (1995): “Reflexiones de un Crítico”, en ALONSO, María Nieves; RODRÍGUEZ, Mario; TRIVIÑOS, Gilberto (Eds.) (1995): La Crítica Literaria Chilena. Concepción, Anibal Pinto., pp. 113-117.

HABERMAS, Jürgen (2006): Historia y Crítica de la opinión pública. La transformación estructural de la vida pública. Barcelona, Gustavo Gili.

JOFRÉ, Manuel (1997): Teoría Literaria y Semiótica. Santiago de Chile, Ed. Universitaria.

LARRAIN, Jorge (2005): ¿América Latina moderna?. Santiago de Chile, LOM.

NITRIHUAL, Luis (2006): "La crítica literaria de Alone y su relación con la problemática de género. Una mirada a la obra de Gabriela Mistral y Marta Brunet”. Revista del Grupo de Investigación Escritoras y Escrituras, $\mathrm{n}^{\circ}$ 4, en línea http://www.escritorasyescrituras.com/revista.php/4/31.

RIVERA, Jorge (1995): El periodismo cultural. Buenos Aires, Paidós.

SAID, Edward (2008): El mundo, el texto y el crítico. Barcelona, DeBolsillo.

SANTAMARÍA SUÁREZ, Luisa y CASALS CARRO, María Jesús (2000): La opinión periodística. Argumentos y géneros para la persuasión. Madrid, Fragua.

SLOTERDIJK, Peter (2007): En el mundo interior del capital. Para una teoría filosófica de la globalización. Madrid, Siruela. 
SLOTERDIJK, P. (2002): El desprecio de las masas. Valencia, Pre-textos.

SULLÀ, Enric (Comp.) (1998): "El debate sobre el canon literario” en SULLÀ, E. (1998): El canon literario. Madrid, Arco/Libros, pp.11-34.

VIDAL, Hernán (1998): La Crítica Literaria como defensa de los Derechos Humanos. Georgia Southern University, EE.UU, Ed. Juan de la Cuesta Hispanic Monographs.

WILLIAMS, Raymond (2008): Palabras clave. Un vocabulario de la cultura y la sociedad. Buenos Aires, Ediciones Nueva Visión. 